Article

\title{
Model to Evaluate Pro-Environmental Consumer Practices
}

\author{
Wendolyn Aguilar-Salinas ${ }^{1}$, Sara Ojeda-Benitez ${ }^{2, *}$, Samantha E. Cruz-Sotelo ${ }^{1}$ and \\ Juan Ramón Castro-Rodríguez ${ }^{3}$ \\ 1 Facultad de Ingeniería Universidad Autónoma de Baja California 1, Mexicali 21280, Mexico; \\ aguilar.wendolyn@uabc.edu.mx (W.A.-S.); samantha.cruz@uabc.edu.mx (S.E.C.-S.) \\ 2 Instituto de Ingeniería, Universidad Autónoma de Baja California 2, Mexicali 21280, Mexico \\ 3 Facultad de Ciencias Químicas e Ingeniería, Universidad Autónoma de Baja California 3, \\ Tijuana 22390, Mexico; rcastror@uabc.edu.mx \\ * Correspondence: sara.ojeda.benitez@uabc.edu.mx; Tel.: +52-686-566-4150
}

Academic Editor: Yu-Pin Lin

Received: 30 December 2016; Accepted: 1 February 2017; Published: 6 February 2017

\begin{abstract}
The consumer plays a key role in resource conservation; therefore, it is important to know consumer behavior to identify consumer profiles and to promote pro-environmental practices in society that encourage resource conservation and reductions in waste generation. The purpose of this paper is to implement a fuzzy model to evaluate consumer behavior in relation to three pro-environmental practices that can be implemented at the household level, including reductions in resource consumption (reduce), reuse of resources (reuse), and recycling (recycle). To identify socio-demographic profiles that characterize an environmentally responsible consumer, 2831 surveys were applied on a representative sample of consumers residing in a Mexican city. Fuzzy logic and neural networks were applied using a Sugeno-type subtractive clustering to determine each profile. The model input variables were socioeconomic status, age, education level, monthly income, occupation and the type of organizations with which the consumer is affiliated. The output variables were represented by pro-environmental practices. Results show that the consumer practices are performed independently of each other, with the most frequent pro-environmental consumer practices being reduction and reuse.
\end{abstract}

Keywords: consumer; pro-environmental practices; fuzzy model; reduction; reuse and recycling

\section{Introduction}

Rapid population growth, urbanization, industrialization, and economic development have resulted in the generation of an enormous volume of solid waste in residential areas throughout the world, particularly within the rapidly growing cities of the developing world [1]. Waste generation is a growing concern for both developing and developed countries. Population growth and wealth have resulted in an increase in product consumption and, most importantly, in waste after product disposal [2]. This increased consumption causes a major challenge for cities because a slight increase in income may cause changes in the consumption patterns of people, leading to the generation of different types and volumes of waste [3].

Tadesse [4] notes that one way to curb this problem is to promote concern for the environment, which allows for controlling waste from the source while seeking adequate separation and disposal practices. Kurisu and Bortoleto [5] indicate that waste generation is closely related to product consumption, causing environmental problems, including greenhouse gases. In certain countries, such as Japan, it is estimated that the domestic sector contributes up to $20 \%$ of this problem, meaning that it is necessary to increase the awareness of citizens to promote the "3Rs" (reduce, reuse, 
and recycle). In a recent article, Purcell and Magette [6] reported that consumers identified solid waste management as an important issue that must be addressed; in particular, practices related to reduction in consumption and recycling must be implemented [7]. These practices are a key factor in the building of a sustainable society [5].

Reduction practices have significant value in this regard [8,9] because a reduction in the consumption of products directly decreases the amount of waste that goes to the final disposal sites [7,9], extending the useful life of the landfill. However, this practice is difficult to promote because its realization usually requires a major adjustment in lifestyle [10]; hence, the minimization of solid waste has received less attention than recycling practices [11].

Waste separation is a crucial step in ensuring that waste is reused. However, there is no evidence linking waste separation at the source with waste minimization practices. The separated waste stream depends not only on the behavior of individuals but also on a variety of other factors, such as the waste collection systems, the influence of commercial waste or the quantities of waste generated [12].

Moreover, recycling becomes an alternative to reduce the amount of waste and environmental damage [10], although certain aspects regarding the benefits of recycling and the reuse of materials should be reviewed [7]. Waste recycling can save energy, conserve resources, reduce emissions, and extend the life of landfills [10,13-15].

In different countries, it has been recognized that the most urgent issue associated with solid waste management is the reduction of solid waste at the source in addition to the promotion of recycling materials; this realization has largely been reached because the final disposal of materials has become increasingly complicated $[5,7,10,16]$. Therefore, many companies consider recycling as an opportunity to maximize their benefits and to reduce the environmental impact caused by these materials at their final disposal sites [17]. The problems associated with the growing volumes of generated waste would be less serious if it was observed as a resource and was managed adequately [18]. These issues stimulate interest, both within the research community and among its primary player, the consumer [19]. Such high volumes of waste have caused the depletion of disposal sites [20,21], as well as the high cost of waste collection systems and waste management [22,23], because waste must be handled properly in a way that minimizes the risk to the environment and human health [15]. To minimize this problem, it is not only important, but also imperative, to decrease the generated volumes of solid waste. One way in which this problem has been addressed is by promoting the development of pro-environmental practices in residential environments [5,24].

The objective of this study is to apply a fuzzy model to evaluate consumer behavior based on the development of pro-environmental practices at the household level.

\section{Materials and Methods}

Mexicali, the state capital of Baja California, Mexico, represents approximately $18 \%$ of the total area of the state and $0.7 \%$ of the total area of the country; this percentage corresponds to $13,936 \mathrm{~km}^{2}$, and Mexicali has a population of 936,826 inhabitants [25]. Geographically, Mexicali is located in the northern region of the country and is bordered on the north and east by the United States of America.

In Mexicali, the daily generation of solid waste is between 600 and 800 tons per day; therefore, it is important to know the profiles of the generators of these waste volumes.

To perform research and identify the practices of reducing, reusing, and recycling by consumers, the population was segmented through a socio-demographic variable, socioeconomic stratum. For this purpose, the city was divided into seven strata, proposed by the Municipal Institute for Research and Urban Planning (Instituto Municipal de Investigacion y Planeacion Urbana, IMIP). The strata are residential housing, medium size housing, popular, social interest, popular progressive, precarious, and farms (Table 1). 
Table 1. The characteristics that identify each socioeconomic stratum.

\begin{tabular}{|c|c|}
\hline Stratum & Definition \\
\hline Residential & $\begin{array}{l}\text { In this stratum, housing is a single-family home, the entries are framed by large gates with } \\
\text { gardens, their roads are wide, the green areas are forested and in constant maintenance; } \\
\text { for remodeling facades, these residences have internal rules to preserve the architectural } \\
\text { style, range of colors and building materials. These are houses from } 300 \text { to } 450 \mathrm{~m}^{2} \text {; } \\
\text { the number of lots per hectare is } 13 \text { to } 19 .\end{array}$ \\
\hline Medium & $\begin{array}{l}\text { The type of housing that corresponds to this stratum is also a single-family home; } \\
\text { commercial and/or service areas are not allowed. These houses measure } 225 \mathrm{~m}^{2} \text { in size; } \\
\text { the number of lots per hectare is } 26 .\end{array}$ \\
\hline Popular & $\begin{array}{l}\text { Predominantly single-family homes, allowing commercial and/or service areas in } 10 \% \text { of } \\
\text { the total salable surface. The ceilings are manufactured of lightweight materials. } \\
\text { The houses are } 180 \mathrm{~m}^{2} \text {, and } 32 \text { lots exist per hectare. }\end{array}$ \\
\hline Social interest & $\begin{array}{l}\text { The predominant use is single-family homes with one parking place; } 15 \% \text { of the total } \\
\text { surface is salable for commercial areas. These houses are } 120 \mathrm{~m}^{2} \text { with } 48 \text { lots per hectare. }\end{array}$ \\
\hline $\begin{array}{l}\text { Popular } \\
\text { progressive }\end{array}$ & $\begin{array}{l}\text { These houses have the same characteristics as those of Social Interest. The houses are } \\
\text { implemented progressively through an introductory program of services and housing } \\
\text { construction, including finished houses (with the house footer) and economic prototypes } \\
\text { with insulating materials. }\end{array}$ \\
\hline Precarious & $\begin{array}{l}\text { These spaces contain illegal dumping along the margins of dirt roads, abandoned drains, } \\
\text { and large vacant lots that are located in the periphery of the city. }\end{array}$ \\
\hline Farms & $\begin{array}{l}\text { These lots contain residential use and are located outside the urban area with a maximum } \\
\text { density of five houses per hectare. }\end{array}$ \\
\hline
\end{tabular}

We determined the number of households by socioeconomic stratum to establish the sample size to an accuracy of $90 \%$. The number of households to be surveyed by stratum was determined from the sample size, with 1800 households expected to be formally surveyed; however, a total of 2831 households were surveyed due to the large number of participants. To administer the survey to the population face to face, a simple random sampling was performed, selecting the neighborhoods that homogeneously represent the stratum. Due to the growth that the city has experienced, some neighborhoods are very heterogeneous, with the households inside belonging to different strata.

To evaluate the pro-environmental practices of consumers (3Rs), it was necessary to identify the input variables using an instrument. The following variables were included in the analysis, including socio-demographic, management, collection, and treatment of waste, as well as the development of pro-environmental practices within the household.

\section{The Fuzzy Model Used to Identify the Pro-Environmental Consumer Behavior Profiles}

To identify the variables that determine the consumer profile behavior with respect to environmental practices, the socio-demographic characteristics of the consumer that influence the development of pro-environmental practices were examined. These characteristics include social stratum, age, education, monthly income, occupation, and the affiliation to organizations.

Table 2 shows the data matrix with the input variables, $X=\left(x_{1}, \ldots, x_{6}\right)$, which correspond to the questions that evaluate the consumer practices of reduction in consumption, reuse of resources and recycling. Table 3 also shows the output variables, $Y_{i}=\left(y_{1}, y_{2}, y_{3}\right)$, that correspond to the development of the 3Rs of pro-environmental practices (reduce, reuse, and recycle). This matrix combines the consumer characteristics with the data related to the pro-environmental practices used to define groups (clusters) that meet a similar profile and, subsequently, to obtain rules and define consumers profiles. 
Table 2. Socio-demographic profiles associated with the development of 3Rs (INPUTS).

\begin{tabular}{|c|c|c|}
\hline $\begin{array}{c}\text { INPUT } \\
\text { Variables }\end{array}$ & Simbology & Description \\
\hline Social Stratum & $X_{1}$ & $\begin{array}{l}\text { Residential } \\
\text { Medium } \\
\text { Popular } \\
\text { Social interest } \\
\text { Popular progressive } \\
\text { Precarious } \\
\text { Farms }\end{array}$ \\
\hline Age & $X_{2}$ & $\begin{array}{l}\text { Less than } 30 \text { years } \\
\text { Between } 30 \text { and } 50 \text { years } \\
\text { Less than } 60 \text { years } \\
\text { Older than } 60 \text { years }\end{array}$ \\
\hline $\begin{array}{l}\text { Monthly } \\
\text { Income }\end{array}$ & $X_{3}$ & $\begin{array}{l}\text { Less than } \$ 539.00 \\
\$ 540.00-\$ 920.00 \\
\text { More than } \$ 921.00\end{array}$ \\
\hline Education & $X_{4}$ & $\begin{array}{l}\text { Elementary school } \\
\text { Middle } \\
\text { Professional }\end{array}$ \\
\hline Occupation & $X_{5}$ & $\begin{array}{l}\text { Students } \\
\text { Employees } \\
\text { Professionals }\end{array}$ \\
\hline Affiliation & $X_{6}$ & $\begin{array}{l}\text { Workgroup } \\
\text { Group of friends } \\
\text { Scientific associations } \\
\text { Church }\end{array}$ \\
\hline
\end{tabular}

Table 3. Practices associated with the pro-environmental behavior development (OUTPUT).

\begin{tabular}{cc}
\hline $\begin{array}{c}\text { OUTPUT Variables } \\
\text { Pro-Environmental 3Rs Practices }\end{array}$ & Simbology \\
\hline Reduce & $Y_{1}$ \\
Reuse & $Y_{2}$ \\
Recycle & $Y_{3}$ \\
\hline
\end{tabular}

The matrix shows nine attributes of which six variables describe the consumer characteristics (input variables) and three describe the level at which consumer makes pro-environmental practices (output variables). To explain the consumer pro-environmental behavior, were used a Sugeno-type subtractive clustering to identify the knowledge base of a fuzzy model systematically with fuzzy reasoning according to Takagi-Sugeno-Kang (TSK) model [26].

The knowledge base of TSK fuzzy model for the consumer pro-environmental behavior is a set of consistent rules of IF antecedents and THEN consequents, where the antecedents of the rules contain linguistic values defined by fuzzy sets, which are characterized by Gaussian membership functions. Additionally, the consequents of rules are linear functions, which are defined as shown in Equations (1-3).

$$
\begin{gathered}
R^{k}: \text { IF } x_{1} \text { is } \widetilde{F}_{1}^{k} \text { and } \ldots x_{i} \text { is } \widetilde{F}_{i}^{k} \text { and } \ldots x_{n} \text { is } \widetilde{F}_{n}^{k} \text { THEN } y \text { is } g^{k}\left(x_{i}\right) \\
\mu_{\widetilde{F}_{i}^{k}}\left(x_{i}\right)=\exp \left[-\frac{1}{2}\left(\frac{x-m_{\widetilde{F}_{i}^{k}}}{\sigma_{\widetilde{F}_{i}^{k}}}\right)^{2}\right] \\
g^{k}\left(x_{i}\right)=c_{1}^{k} x_{1}+\ldots+c_{i}^{k} x_{i}+\ldots+c_{n}^{k} x_{n}+c_{0}^{k}
\end{gathered}
$$


where $\sigma_{\widetilde{F}_{i}^{k}}, m_{\widetilde{F}_{i}^{k}}$ are parameters of the membership functions, $\mu_{\widetilde{F}_{i}^{k}}\left(x_{i}\right)$, the antecedents of rules, and $c_{i}^{k}$ are parameters of linear functions of consequents of the fuzzy rules, $g^{k}\left(x_{i}\right)$ for the $k$ th rule $(k=1,2$, $\ldots, 10)$ and $i$ th input $(i=1,2, \ldots, 6)$.

The TSK fuzzy model for the consumer pro-environmental behavior was obtained by the inference process of knowledge base, as well to system inputs according to Equation (4):

$$
y(x)=\sum_{k=1}^{10} \phi^{k}(x) g^{k}(x)
$$

where $\phi^{k}(x)$ is given by Equation (5):

$$
\phi^{k}(x)=\frac{\alpha^{k}(x)}{\sum_{\ell=1}^{10} \alpha^{\ell}(x)}
$$

where $\alpha^{k}(x)$ is given by Equation (6):

$$
\alpha^{k}(x)=\prod_{i=1}^{6} \mu_{\widetilde{F}_{i}^{k}}\left(x_{i}\right)
$$

Fuzzy logic-based systems allow the incorporation of numerical and linguistic information in a systematic way. Allows representing the behavior or dynamic of those systems through rules diffuse of the type IF-THEN, so that a system diffuse allows modeling systems not linear, and learn of them data making use of certain algorithms of learning.

The process of clustering is an automatic learning technique, which consists of the division of data into groups of similar characteristics.

Suppose we do not have a clear idea how many clusters there should be for a given set of data. Subtractive clustering is an algorithm for estimating the number of clusters and the cluster centers in a set of data. The cluster estimates obtained from the subclust function can be used to initialize iterative optimization-based clustering methods and model identification methods. The subclust function finds the clusters by using the subtractive clustering method.

This method is used to explore similarities and differences between two or more sets of multidimensional data. When applying subtractive clustering, each centroid represents a prototype or profile that exhibits certain characteristics of system modeling. These centers of the conglomerates are used as the premise of fuzzy rules.

The components or stages of a diffuse system, as it shows in Figure 1 are:

1. Fuzzification: This interface to each input variable is assigned a grade of membership (or membership function) to each of the fuzzy sets that have been considered.

2. Knowledge base: the membership functions define of fuzzy sets used in Fuzzy rules and establish a link logic between the degrees of membership of the different input variables.

3. Inference engine: consists in quantifying each premise, which is the application of the fuzzy operator (AND) in the antecedent and active the rules that are the application of the method of involvement or the conclusion of the rule. In this case, the method used is inference from Takagi-Sugeno.

4. Defuzzification, consists in passing the grade of membership, coming from consequence of the inference rule, to an actual value. 

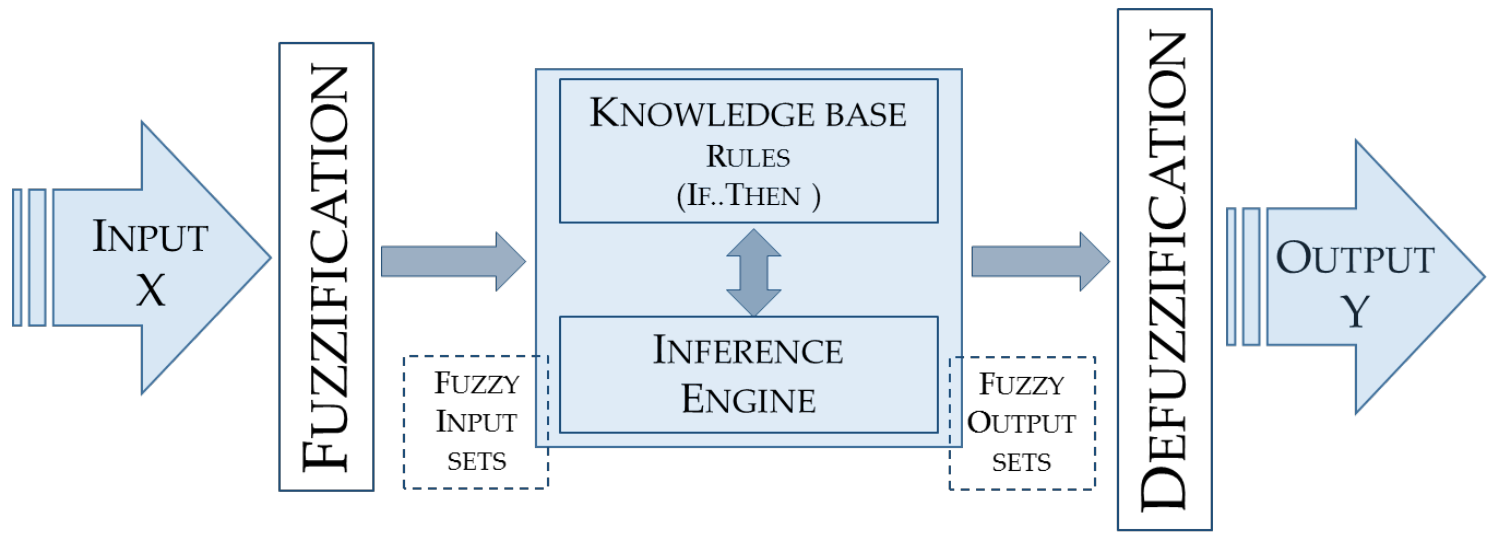

Figure 1. Structure identification of fuzzy model.

\section{Results}

Variables were analyzed and related to the development of consumer pro-environmental practices at the household level (reduction, reuse, and recycling) and became inputs for the model. These variables were analyzed in a range from one to five, with the rank of one corresponding to correct environmental behavior and increasing until reaching an incorrect behavior.

Table 4 shows the results of the exploratory statistical analysis. It should be noted that recycling has a slight negative bias, indicating that it is skewed to negative values (the mode is greater than the mean and median). The reduction in consumption and reuse showed a positive bias, indicating that the most extreme data are above average, skewed to positive values. All variables showed a reduced concentration around the core values of distribution (platykurtic distribution). However, the deviation in symmetry was not sufficiently removed from zero to be considered significant.

Table 4. A statistical analysis of the system input variables.

\begin{tabular}{cccc}
\hline Statistical Variables & Reduce & Reuse & Recycle \\
\hline Mean & 2.16 & 2.54 & 3.22 \\
Median & 2.20 & 2.33 & 3.25 \\
Standard Deviation & 0.733 & 0.801 & 0.454 \\
Variance & 0.537 & 0.642 & 0.206 \\
Skewness & 0.405 & 0.245 & -0.177 \\
Kurtosis & 0.004 & 0.299 & 0.590 \\
\hline
\end{tabular}

The degree of co-variation between variables that were related linearly was measured with the Pearson correlation coefficient. Using the correlation matrix, the intensity ratio between dependent variables was determined (Table 5). It should be noted that there is no linear relationship between the output variables; this result means that the consumer performs these practices independently of each other. In human phenomena, which are heavily laden with random components, it is usually not possible to establish exact functional relationships.

Table 5. Correlation matrix.

\begin{tabular}{cccc}
\hline$n=2830$ & Reduction & Reuse & Recycle \\
\hline Reduction & 1 & & \\
Reuse & $0.432^{* *}$ & 1 & \\
Recycle & $0.306^{* *}$ & $0.301^{* *}$ & 1 \\
\hline Note: ${ }^{* *}$ Correlation is significant at the 0.01 level (two-tailed).
\end{tabular}


In Table 6, there are three levels that a consumer can have for pro-environmental practices. The percentage performances of each practice were analyzed based on the population to identify consumers' behavior with respect to the 3Rs. Results show the practices of the 3Rs that consumers perform are reduction and reuse.

Table 6. Practice level of 3Rs based on consumer behavior.

\begin{tabular}{cccc}
\hline Consumer Level & Reduction & Reuse & Recycle \\
\hline Performed & $68 \%$ & $51.7 \%$ & $1.7 \%$ \\
Indifferent & $28.3 \%$ & $36.1 \%$ & $53.8 \%$ \\
Not performed & $3.7 \%$ & $12.2 \%$ & $44.5 \%$ \\
\hline
\end{tabular}

\subsection{Consumer Pro-Environmental Behavior}

Pro-environmental consumer behavior was analyzed using a fuzzy model formulated through the Fuzzy Logic Toolbox of MATLAB ${ }^{\circledR}$ R2009b (MathWorks Inc, Sunnyvale, CA, USA), and it provided the elements and criteria for subsequent data analysis. This model contains socio-demographic characteristics that influence the consumer behavior and practices associated with the 3Rs.

The model was obtained both by clustering the consumers' demographic data and by the development of pro-environmental practices to reduce, reuse and recycle. The model was constructed of six input variables (from $X_{1}$ to $X_{6}$ ), which identified socio-demographic consumer characteristics, and three output variables in the proposed fuzzy system $\left(Y_{1}\right.$ to $\left.Y_{3}\right)$, which determined the extent of the realization of the pro-environmental practices (Table 3). The structure of the TSK fuzzy model was derived based on subtractive clustering, generating parameters of membership functions for each input and output linguistic variable, in addition to the basis of the TSK fuzzy rule system. Variables related to the development of pro-environmental practices in the household $\left(Y_{1}, Y_{2}\right.$ and $\left.Y_{3}\right)$ were evaluated in a valuation range from one to five, scoring from positive to negative in relation to the practice evaluated.

Figure 2 describes the TSK fuzzy model architecture based on the dataset of independent variables (stratum, age, education, monthly income, occupation, affiliations) and dependent variables (reduce, reuse, and recycle). Membership functions generated by the model were used to detect categories in which a majority of the population occurred such that a portion of the variables could be categorized.

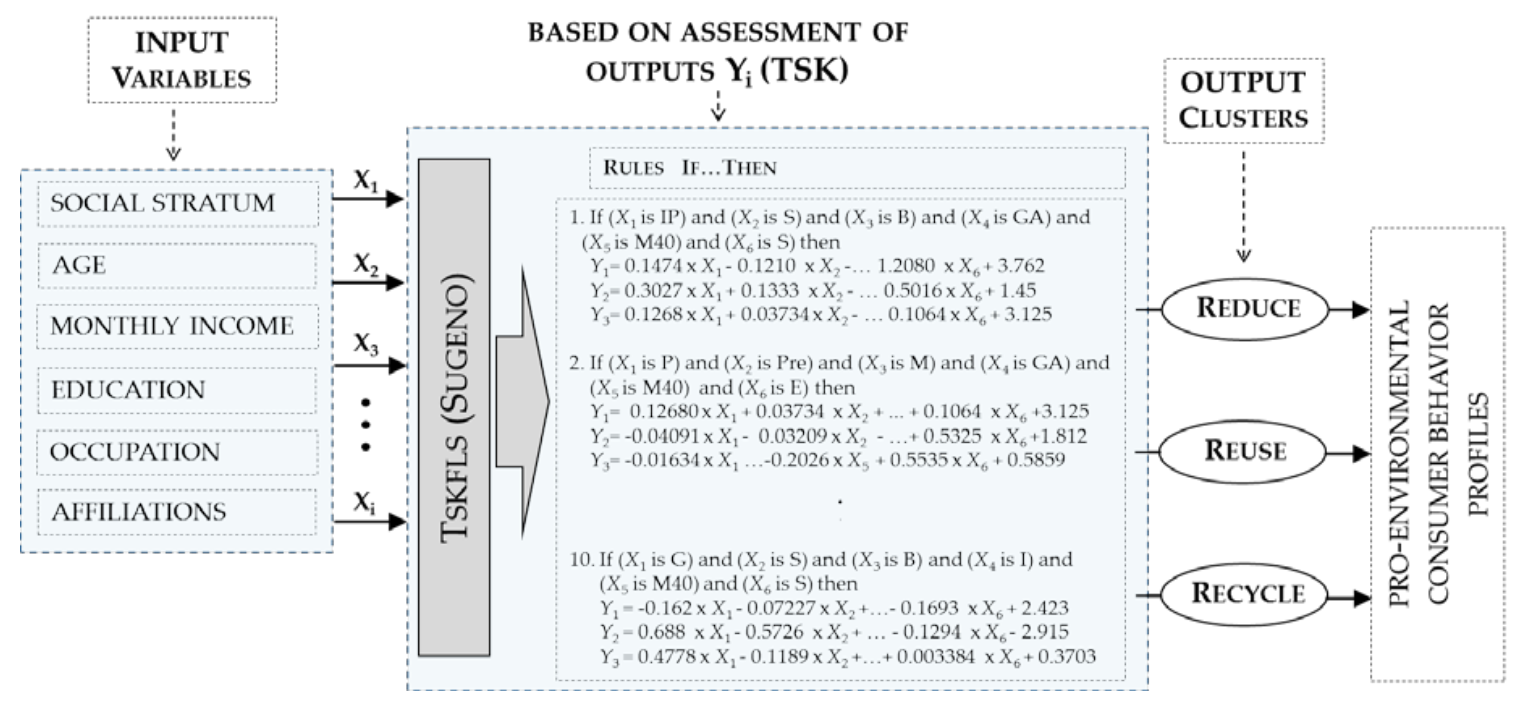

Figure 2. Fuzzy model architecture to evaluate consumer pro-environmental behavior. 
To determine a behavioral profile and to identify consumer pro-environmental practices, it was necessary to establish the predictive variables. To this end, all relationships between the socio-demographic characteristics of the consumer and the development of 3Rs practices were analyzed.

As an example, in Figure 3, the analyses for the dependent variable "reduction in consumption" based on the independent variable "socioeconomic stratum", and its relation with other demographic variables, were reported. The range of colors indicates whether a performed practice is positive or negative, with blue identifying a positive practice and brown identifying a negative practice. This figure shows that the stratum variable is determinant in its relation to the reduction in consumption, determining consumers that perform this pro-environmental practice at all times and enhancing the development of the reduction practice when the stratum is high. One can observe how, in relation to educational level, reduction is shown to be positive when the stratum is high, and the education level is low. However, this behavior was found to be negative when analyzing the lower stratum and increasing the education level. At a medium to high stratum with incomes above $\$ 920.00$, reduction is positive. In the lower stratum (particularly farms), we observed an absence of the reduction practice when the monthly income is between $\$ 540.00$ and $\$ 920.00$. An important pattern is shown in relation to the socioeconomic stratum and consumer age, demonstrating that reduction in consumption increases if the stratum increases and the consumer age decreases. That is, the youngest individuals are mostly likely to develop this practice.

(a)

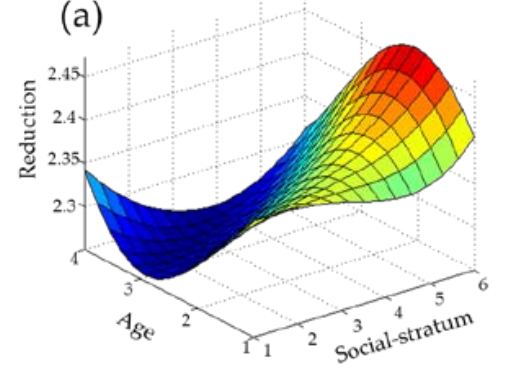

(b)

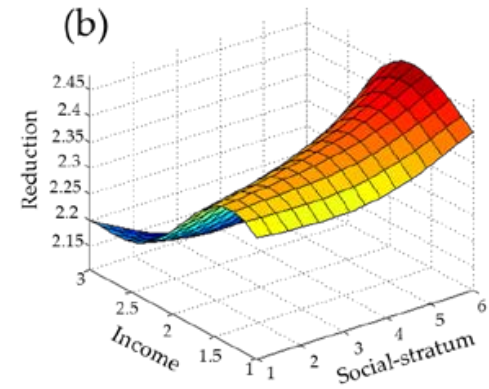

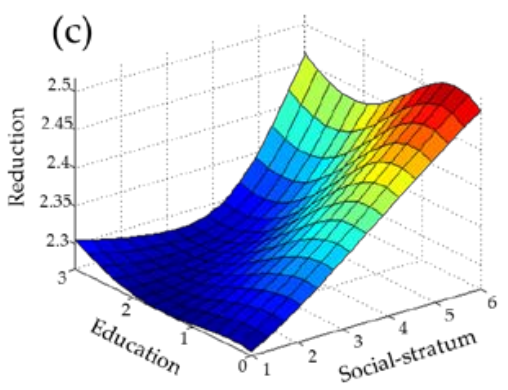
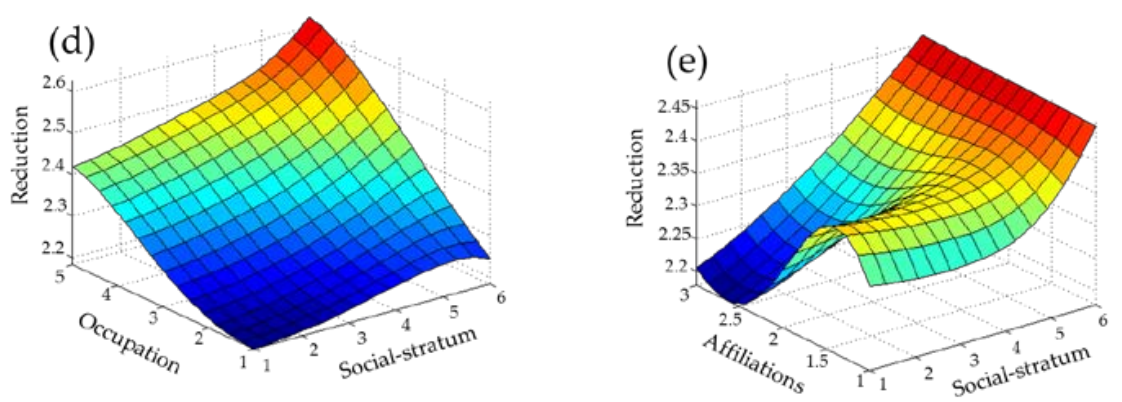

Figure 3. Reduction practices in consumption. Relationship between social stratum and (a) age; (b) monthly income; (c) education; (d) occupation; and (e) affiliations.

For the determination of the rules that allow identification of which socio-demographic characteristics are relevant to explain the behavior of the $3 R s$, it was necessary to verify relations that explain each behavior. Each group to be created has the same antecedent rule because the output is a binarized vector $Y=\left[Y_{1}, Y_{2}, Y_{3}\right]$ where each element of the array has values of $[1,5]$. For each practice, a value of one gives a positive value and five gives a negative value.

Ten fuzzy rules were generated; each rule shows the constant values of the consequents in linear function form, thereby allowing every consumer profile found to be defined (see Appendix A and Table A1). 


\subsection{Consumer Profiles Based on 3Rs Practices}

After evaluating each rule of the fuzzy model, each behavioral profile was identified based on 3Rs development, identifying three clusters (Table 7).

Table 7. Consumers' environmental practices as related to types of behavior.

\begin{tabular}{cccc}
\hline \multirow{2}{*}{ Pro-Environmental Practices } & \multicolumn{3}{c}{ Behavior Profiles } \\
\cline { 2 - 4 } & Cluster 1 & Cluster 2 & Cluster 3 \\
\hline Reduce & 2 & 2 & 2 \\
Reuse & 2 & 3 & 3 \\
Recycle & 3 & 3 & 1 \\
\hline
\end{tabular}

Table 8 contains the definition of each cluster. Clustering allowed exact patterns in the dataset to be found.

Table 8. Definition of consumers' environmental behavior scale, based on 3Rs practices.

\begin{tabular}{ccl}
\hline Level & Cluster & Definition \\
\hline Concerned & 1 & $\begin{array}{l}\text { A consumer who is concerned about conservation of the } \\
\text { environment and performs reduce and reuse practices. } \\
\text { Prone to developing the recycling practice. }\end{array}$ \\
\hline Indifferent & 2 & $\begin{array}{l}\text { A consumer whose performance is indifferent with } \\
\text { respect to caring for the environment such that they } \\
\text { demonstrate this attitude when dealing with the practice of } \\
\text { reuse and recycling (occasionally). }\end{array}$ \\
\hline Not concerned & 3 & $\begin{array}{l}\text { A consumer who considers a reduction in consumption but is } \\
\text { indifferent to the notion of product reuse. Additionally, } \\
\text { the consumer's attitude toward recycling is passive. }\end{array}$ \\
\hline
\end{tabular}

After determining the profiles, percentages found for each assessment relative to the performance of pro-environmental practices in the household (Table 9) were observed, with the goal of identifying those that appear in the majority of the population. Based on our observations, the population is distributed evenly, concentrating a higher indifference percentage in pro-environmental development practices (3Rs).

Table 9. Environmental performance assessment based on the 3Rs.

\begin{tabular}{cc}
\hline Environmental Behavior & Percentage \\
\hline Concerned & $35.4 \%$ \\
Indifferent & $36.4 \%$ \\
Not concerned & $28.2 \%$ \\
\hline
\end{tabular}

Table 10 shows the consumer demographic information associated with the types of behaviors found in the population. Specific social and demographic characteristics were identified in consumers, as associated with the behavior of a particular pro-environmental practice. 
Table 10. Socio-demographic variables associated at environmental behavior profiles.

\begin{tabular}{llll}
\hline $\begin{array}{l}\text { Socio-Demographic } \\
\text { Characteristics }\end{array}$ & Environmental Behavior Profiles & & Not concerned \\
\cline { 2 - 4 } $\begin{array}{l}\text { Socioeconomic stratum } \\
\text { (type of housing })\end{array}$ & $\begin{array}{l}\text { Residential, medium, popular, } \\
\text { social interest, popular } \\
\text { progressive, precarious }\end{array}$ & Popular & $\begin{array}{l}\text { Social interest } \\
\text { and farms }\end{array}$ \\
\hline Education level & $\begin{array}{l}\text { Elementary school, middle school } \\
\text { and professional }\end{array}$ & $\begin{array}{l}\text { High school and } \\
\text { Professional }\end{array}$ & $\begin{array}{l}\text { Elementary school } \\
\text { and middle school }\end{array}$ \\
\hline Monthly income & $\begin{array}{l}\text { Less than } \$ 540.00 \text { and } \\
\text { more than } \$ 921.00\end{array}$ & More than $\$ 540.00$ & Less than $\$ 540.00$ \\
\hline Affiliations & $\begin{array}{l}\text { Group of friends, scientific } \\
\text { associations and church }\end{array}$ & Work group and friends & $\begin{array}{l}\text { Work group } \\
\text { and church }\end{array}$ \\
\hline Age & Less than 60 years & Between 30 and 50 years & $\begin{array}{l}\text { Less than } 30 \text { and } \\
\text { older than } 60 \text { years }\end{array}$ \\
\hline Occupation & None, lecturer and professionals & & $\begin{array}{l}\text { None, employees } \\
\text { and students }\end{array}$ \\
\hline
\end{tabular}

\section{Discussion}

In this paper, the consumer behavior associated with the development of 3Rs practices is analyzed to identify behavioral patterns in consumers. Results show that it is possible to identify groups associated with the development levels of these practices. Socio-demographic characteristics specific to each group are described.

Regarding the development of 3Rs practices, it has been shown that the reduction practice in consumption is less appreciated by researchers [11] when compared to recycling $[10,21,24,27]$. However, reductions in consumption are more appreciated by consumers because it has been shown that $68 \%$ of the population practices different behaviors, such as purchasing products with less packaging and, thus, reducing consumption amounts and unnecessary products, among others. Barr, Gil and Ford [28] found that reuse is practiced more often by senior citizens, unlike the findings of this study, in which people over 60 were found to be indifferent, while younger individuals practice reuse more often.

Waste separation at the source is necessary for reusing and recycling materials [4,29]. However, there are many factors influencing this, limiting its development $[10,24,30]$ and preventing the development of the recycling practice.

Solid waste recycling increases landfill and disposal site life spans, reducing the waste amount sent to these sites $[10,15,24]$. Recycling can contribute to the cities', states', or countries' economies because recycled materials can be transformed into energy or raw materials for the industrial sector [31]. Recycling is an essential practice in a society that demands environmental conservation; however, it was observed here that recycling is not valued by the population, with the findings of this study showing that $1.7 \%$ of consumers practice recycling. Some studies show that factors such as education level and age have no relevance in determining recycling practice [9], showing these factors do not exhibit significant differences with respect to recycling practices [24]. Unlike the findings of Kelly et al. [32], who found that age had a significant relationship with recycling behavior, young people tend to be indifferent (sometimes recycle), and middle-aged groups tend to recycle more frequently. Moreover, it was found that young people with low education levels define the population sector not practicing recycling [28], while people with higher incomes tend to be more active in recycling [10]. Additionally, Barr et al. [28], found that people who recycle are difficult to identify demographically.

In this study it was difficult to identify the socio-demographic characteristics of consumers that perform recycling behaviors. This finding is observed due to the low participation of the population in this practice: the participants studied here were widely dispersed in age (under 60) and had jobs as teachers or professionals, ranging from extremely low incomes to high incomes. In previous studies [33-35], a relationship has been established between socio-demographic characteristics such 
as the level of income and education with the practice of recycling. Nonetheless, no relationship was found in this research given that, of the three practices evaluated, recycling is at a disadvantage due to the lack of reference group as reported [36]. In addition, the consumers interviewed have little knowledge of recycling and its challenges.

It is important to mention that the use of a fuzzy clustering technique showed a high potential for learning and predicting recycling behaviors, using a fast interface that was easy to operate [37], and finding a correlation between the experimental data and the values predicted by the model [38]. The motivation for preferring fuzzy modeling instead of other techniques is the ability to use vague and imprecise information that can be used in complex, nonlinear, and multivariate problems [39]. This research agrees with the results presented by Vesely [40], who points out that modeling the recycling behavior with fuzzy logic can provide a better tool to predict the behavior. Our results confirm that fuzzy logic can be an interesting alternative method to explain environmental behaviors. According to [40-42], fuzzy logic modeling opens new possibilities for predicting environmental behaviors. Also, it can be used for planning and evaluation of environmental policies and environmentally friendly production, waste management and the development of decision support tools.

\section{Conclusions}

Generally, in the development of pro-environmental practices, the population showed an attitude of indifference for these practices. This finding demonstrates the low participation that consumers have in activities related to the environmental conservation of a city. The creation of recycling companies for materials that are generated mostly at home can produce a change in the lifestyle of consumers, considering recycling as an opportunity to maximize revenue and reduce solid waste generation.

To identify socio-demographic profiles that explain the consumer behaviors aimed at developing pro-environmental practices, it was necessary to develop both a fuzzy model, which included six input variables for socio-demographic characteristics, and a vectorized output for pro-environmental practices (reduce, reuse, recycle), with 10 fuzzy rules being used for each output value.

With this model, three patterns of behavior were identified based on the development of 3Rs practices, which allowed the behavior of each type of consumer to be observed. With this assessment, studies may be conducted to identify reasons that induce the consumer to act or not act in a pro-environmental manner. This analysis will also allow educational campaigns regarding the performance of pro-environmental practices to be directed to the most vulnerable population at the household level. The results show that it is important to continue the research that has been approached in this work, because with fuzzy tools and knowledge bases, a new model can be proposed to raise the awareness of the population in the use of resources.

No linear relationship was identified in the development of these practices such that one can be developed without performing the other.

The advantage of applying artificial intelligence techniques in data analysis is that fuzzy logic gives a linguistic model based on the consumer's knowledge.

The complicated aspect is the selection of parameters for modeling the problem. The subtractive clustering algorithm made possible the adaptation of these parameters according to actual data because the algorithm takes advantage of the learning capabilities of an artificial neural network and fuzzy logic modeling superiority, allowing an estimation of parameter membership functions and consequential functions.

The high level of uncertainty is characteristic of linguistic-type variables and of the valuation given by the consumer to ecological consumption. The rules for analyzing the input variables were generated with respect to the output variable, allowing for a selection of the optimal number of training data to build the model. Subsequently, this result enabled the generation of demographic profiles that clearly identify variables influencing the development of 3Rs practices. Consequently, this finding also 
enables environmental protection by consumers, in addition to allowing consumers the opportunity to develop responsible consumption practices.

For further analysis in the generation of the demographic profiles of consumers, it will be necessary to use variables for changing behaviors, such as attitudes, beliefs, and environmental knowledge, among others.

Author Contributions: Wendolyn Aguilar-Salinas and Sara Ojeda-Benitez wrote the paper. Samantha E. Cruz-Sotelo contributed to writing the manuscript, data analysis and model definition. Juan Ramón Castro provided technical and logistical support in the field and contributed to writing the manuscript. All authors have read and approved the final manuscript.

Conflicts of Interest: The authors declare no conflict of interest.

\section{Appendix A}

Below, the 10 fuzzy rules generated are listed, showing the values of the constants of the linear functions of the consequents of the rules for undertaking these practices, thereby allowing every profile to be evaluated.

1. If $\left(X_{1}\right.$ is IP) and $\left(X_{2}\right.$ is $\left.S\right)$ and $\left(X_{3}\right.$ is $\left.B\right)$ and $\left(X_{4}\right.$ is GA) and ( $X_{5}$ is M40) and $\left(X_{6}\right.$ is $\left.S\right)$, then

$$
\begin{aligned}
& Y_{1}=0.1474 \times X_{1}-0.121 \times X_{2}-1.357 \times X_{3}+0.1782 \times X_{4}-0.1953 \times X_{5}-1.208 \times X_{6}+3.762 \\
& Y_{2}=0.3027 \times X_{1}+0.1333 \times X_{2}-1.336 \times X_{3}+0.4211 \times X_{4}-0.01914 \times X_{5}+0.5016 \times X_{6}+1.45 \\
& Y_{3}=0.1268 \times X_{1}+0.03734 \times X_{2}-0.4666 \times X_{3}+0.1567 \times X_{4}+0.03573 \times X_{5}-0.1064 \times X_{6}+3.125
\end{aligned}
$$

2. If $\left(X_{1}\right.$ is $\left.P\right)$ and ( $X_{2}$ is Pre) and ( $X_{3}$ is M) and ( $X_{4}$ is GA) and ( $X_{5}$ is M40) and ( $X_{6}$ is $\left.E\right)$, then

$$
Y_{1}=0.1268 \times X_{1}+0.03734 \times X_{2}-0.4666 \times X_{3}+0.1567 \times X_{4}+0.03573 \times X_{5}-0.1064 \times X_{6}+3.125
$$$$
Y_{2}=-0.04091 \times X_{1}-0.03209 \times X_{2}-0.05068 \times X_{3}-0.0494 \times X_{4}-0.1112 \times X_{5}+0.5325 \times X_{6}+1.812
$$$$
Y_{3}=-0.01634 \times X_{1}+0.1287 \times X_{2}-0.1379 \times X_{3}+0.09919 \times X_{4}-0.2026 \times X_{5}+0.5535 \times X_{6}+0.5859
$$

3. If $\left(X_{1}\right.$ is $\left.P\right)$ and ( $X_{2}$ is Pre) and ( $X_{3}$ is $\left.M\right)$ and ( $X_{4}$ is GA) and ( $X_{5}$ is $\left.A\right)$ and $\left(X_{6}\right.$ is $\left.S\right)$, then

$$
\begin{aligned}
& Y_{1}=0.2811 \times X_{1}-1.111 \times X_{2}-1.92 \times X_{3}+0.01461 \times X_{4}-0.3293 \times X_{5}+1.302 \times X_{6}+8.425 \\
& Y_{2}=0.2793 \times X_{1}-0.681 \times X_{2}-0.8567 \times X_{3}+0.0983 \times X_{4}-0.1781 \times X_{5}+0.5819 \times X_{6}+5.521 \\
& Y_{3}=0.1648 \times X_{1}-0.4863 \times X_{2}-0.7554 \times X_{3}+0.08676 \times X_{4}-0.06143 \times X_{5}-0.8528 \times X_{6}+6.334
\end{aligned}
$$

4. If $\left(X_{1}\right.$ is $\left.P\right)$ and ( $X_{2}$ is Pro) and ( $X_{3}$ is $\left.A\right)$ and ( $X_{4}$ is GT) and ( $X_{5}$ is $\left.A\right)$ and $\left(X_{6}\right.$ is $\left.P\right)$, then

$$
\begin{aligned}
& Y_{1}=0.002238 \times X_{1}+0.1278 \times X_{2}-0.09034 \times X_{3}-0.1572 \times X_{4}-0.01485 \times X_{5}+0.4349 \times X_{6}+0.9447 \\
& Y_{2}=0.05187 \times X_{1}+0.01945 \times X_{2}+0.183 \times X_{3}-0.7169 \times X_{4}+0.02324 \times X_{5}+0.5918 \times X_{6}+0.4082 \\
& Y_{3}=0.0839 \times X_{1}+0.02264 \times X_{2}+0.1095 \times X_{3}-0.2175 \times X_{4}+0.02366 \times X_{5}+0.2687 \times X_{6}+2.197
\end{aligned}
$$

5. If ( $X_{1}$ is Pre) and ( $X_{2}$ is $\left.P\right)$ and ( $X_{3}$ is $\left.B\right)$ and ( $X_{4}$ is I) and ( $X_{5}$ is $\left.M\right)$ and ( $X_{6}$ is $\left.S\right)$, then

$$
\begin{aligned}
& Y_{1}=0.3091 \times X_{1}+0.04351 \times X_{2}-0.3382 \times X_{3}-0.1807 \times X_{4}+0.1641 \times X_{5}+0.1161 \times X_{6}+0.1156 \\
& Y_{2}=-0.1811 \times X_{1}-0.5693 \times X_{2}-0.6107 \times X_{3}+0.1079 \times X_{4}+0.648 \times X_{5}+0.2133 \times X_{6}+0.8821 \\
& Y_{3}=0.5899 \times X_{1}+0.2088 \times X_{2}-0.1664 \times X_{3}-0.1625 \times X_{4}-0.1494 \times X_{5}+0.05849 \times X_{6}+0.4912
\end{aligned}
$$

6. If ( $X_{1}$ is RM) and ( $X_{2}$ is Pro) and ( $X_{3}$ is $\left.A\right)$ and $\left(X_{4}\right.$ is GA) and ( $X_{5}$ is $\left.A\right)$ and $\left(X_{6}\right.$ is $\left.S\right)$, then

$$
\begin{aligned}
& Y_{1}=0.2786 \times X_{1}-0.7009 \times X_{2}-2.363 \times X_{3}+0.003252 \times X_{4}+0.06166 \times X_{5}+0.2852 \times X_{6}+12.3 \\
& Y_{2}=0.213 \times X_{1}-0.5956 \times X_{2}-1.671 \times X_{3}-0.01695 \times X_{4}+0.08459 \times X_{5}+0.258 \times X_{6}+9.525 \\
& Y_{3}=0.1629 \times X_{1}-0.2864 \times X_{2}-1.465 \times X_{3}+0.03504 \times X_{4}-0.04136 \times X_{5}-0.09205 \times X_{6}+9.379
\end{aligned}
$$

7. If ( $X_{1}$ is IP) and ( $X_{2}$ is $\left.S\right)$ and ( $X_{3}$ is $\left.B\right)$ and ( $X_{4}$ is GT) and ( $X_{5}$ is M40) and ( $X_{6}$ is E), then

$$
Y_{1}=0.003945 \times X_{1}-0.009379 \times X_{2}+0.5911 \times X_{3}+0.4329 \times X_{5}+0.0337 \times X_{6}-0.421
$$


$Y_{2}=0.02499 \times X_{1}-0.0855 \times X_{2}+0.125 \times X_{3}-0.06745 \times X_{4}+0.003295 \times X_{5}-0.2303 \times X_{6}+3.111$

$Y_{3}=-0.02816 \times X_{1}-0.2127 \times X_{2}+0.2183 \times X_{3}-0.0218 \times X_{4}-0.07135 \times X_{5}-0.06195 \times X_{6}+4.051$

8. If $\left(X_{1}\right.$ is $\left.P\right)$ and $\left(X_{2}\right.$ is $\left.P\right)$ and $\left(X_{3}\right.$ is $\left.B\right)$ and $\left(X_{4}\right.$ is $\left.I\right)$ and $\left(X_{5}\right.$ is M60) and $\left(X_{6}\right.$ is $\left.S\right)$, then

$Y_{1}=0.0001317 \times X_{1}-0.4063 \times X_{2}+0.2872 \times X_{3}+0.1214 \times X_{4}-0.1505 \times X_{5}-0.02262 \times X_{6}+3.13$

$Y_{2}=0.3027 \times X_{1}+0.1333 \times X_{2}-1.336 \times X_{3}+0.4211 \times X_{4}-0.01914 \times X_{5}+0.5016 \times X_{6}+1.45$

$Y_{3}=0.6292 \times X_{1}-0.1786 \times X_{2}+0.07931 \times X_{3}+0.08387 \times X_{4}-0.2827 \times X_{5}-0.03024 \times X_{6}+4.18$

9. If $\left(X_{1}\right.$ is $\left.P\right)$ and ( $X_{2}$ is Pro $)$ and $\left(X_{3}\right.$ is $\left.A\right)$ and $\left(X_{4}\right.$ is $\left.I\right)$ and ( $X_{5}$ is $\left.A\right)$ and $\left(X_{6}\right.$ is $\left.P\right)$, then

$Y_{1}=0.1079 \times X_{1}-0.01794 \times X_{2}-0.07268 \times X_{3}-0.1329 \times X_{4}+0.03055 \times X_{5}-0.5873 \times X_{6}+4.378$

$Y_{2}=-0.09826 \times X_{1}-0.218 \times X_{2}-0.269 \times X_{3}-0.8943 \times X_{4}+0.03092 \times X_{5}-0.8447 \times X_{6}+9.629$

$Y_{3}=-0.04441 \times X_{1}-0.01798 \times X_{2}-0.008708 \times X_{3}-0.145 \times X_{4}-0.07247 \times X_{5}-0.8903 \times X_{6}+6.975$

10. If $\left(X_{1}\right.$ is $\left.G\right)$ and $\left(X_{2}\right.$ is $\left.S\right)$ and $\left(X_{3}\right.$ is $\left.B\right)$ and $\left(X_{4}\right.$ is $\left.I\right)$ and $\left(X_{5}\right.$ is M40) and ( $X_{6}$ is $\left.S\right)$, then

$Y_{1}=-0.162 \times X_{1}-0.07227 \times X_{2}+0.2649 \times X_{3}+0.05955 \times X_{4}+0.4396 \times X_{5}-0.1693 \times X_{6}+2.423$

$Y_{2}=0.688 \times X_{1}-0.5726 \times X_{2}+0.2067 \times X_{3}+0.6266 \times X_{4}+0.6097 \times X_{5}-0.1294 \times X_{6}-2.915$

$Y_{3}=0.4778 \times X_{1}-0.1189 \times X_{2}+0.02576 \times X_{3}-0.003127 \times X_{4}+0.1928 \times X_{5}+0.003384 \times X_{6}+0.3703$

Table A1. Variables definition for fuzzy rules.

\begin{tabular}{|c|c|c|c|}
\hline Sets & Variable & Simbology & Values \\
\hline \multirow{6}{*}{ Inputs } & Social stratum & $X_{1}$ & $\begin{array}{l}\text { RM (Residential/Medium) } \\
\text { IP (Social interest/Popular) } \\
\text { P (Popular Progressive) } \\
\text { Pre (Precaroius) } \\
\text { G (Farms) }\end{array}$ \\
\hline & Education level & $X_{2}$ & $\begin{array}{l}\text { P (Elementary) } \\
\text { S (Middle School) } \\
\text { Pre (High School) } \\
\text { Pro (Professional) }\end{array}$ \\
\hline & Monthly income & $X_{3}$ & $\begin{array}{l}\mathrm{B}(<539 \text { USD }) \\
\mathrm{M}(>539 \text { and }<920 \text { USD }) \\
\mathrm{A}(>920 \text { USD })\end{array}$ \\
\hline & Affiliations & $X_{4}$ & $\begin{array}{l}\text { GA (Friends group) } \\
\text { GT (Workgroup) } \\
\text { I (Church Group) }\end{array}$ \\
\hline & Age & $X_{5}$ & $\begin{array}{l}\text { M40 }(<40) \\
\mathrm{A}(>40 \text { and }<50) \\
\mathrm{M}(>50 \text { and }<60) \\
\text { M60 }(>60)\end{array}$ \\
\hline & Occupation & $X_{6}$ & $\begin{array}{l}\text { S (Student) } \\
\text { E (Employee) } \\
\text { P (Professional) }\end{array}$ \\
\hline \multirow{3}{*}{ Outputs } & Reduction & $Y_{1}$ & \\
\hline & Reuse & $Y_{2}$ & \\
\hline & Recycling & $Y_{3}$ & \\
\hline
\end{tabular}

Example:

If $\left(X_{1}\right.$ is IP) and $\left(X_{2}\right.$ is $\left.S\right)$ and $\left(X_{3}\right.$ is $\left.B\right)$ and $\left(X_{4}\right.$ is GA) and ( $X_{5}$ is M40) and $\left(X_{6}\right.$ is $\left.S\right)$, then $Y_{1}=0.1474 \times X_{1}-0.121 \times X_{2}-1.357 \times X_{3}+0.1782 \times X_{4}-0.1953 \times X_{5}-1.208 \times X_{6}+3.762$ 
$Y_{2}=0.3027 \times X_{1}+0.1333 \times X_{2}-1.336 \times X_{3}+0.4211 \times X_{4}-0.01914 \times X_{5}+0.5016 \times X_{6}+1.45$

$Y_{3}=0.1268 \times X_{1}+0.03734 \times X_{2}-0.4666 \times X_{3}+0.1567 \times X_{4}+0.03573 \times X_{5}-0.1064 \times X_{6}+3.125$

If (Social stratum $=$ Social interest or Popular) AND (Education level $=$ Middle School) AND (Monthly income is $<539$ USD) AND (Affiliations = Friends group) AND (Age < 40) AND (Occupation = Student) THEN

Reduction $\left(Y_{1}\right)=0.1474 \times X_{1}-0.121 \times X_{2}-1.357 \times X_{3}+0.1782 \times X_{4}-0.1953 \times X_{5}-1.208 \times X_{6}+3.762$

Reuse $\left(Y_{2}\right)=0.3027 \times X_{1}+0.1333 \times X_{2}-1.336 \times X_{3}+0.4211 \times X_{4}-0.01914 \times X_{5}+0.5016 \times X_{6}+1.45$

Recycling $\left(Y_{3}\right)=0.1268 \times X_{1}+0.03734 \times X_{2}-0.4666 \times X_{3}+0.1567 \times X_{4}+0.03573 \times X_{5}-0.1064 \times X_{6}$ $+3.125$

\section{References}

1. Afroz, R.; Masud, M.M. Using a contingent valuation approach for improved solid waste management facility: Evidence from Kuala Lumpur, Malaysia. Waste Manag. 2011, 31, 800-808. [CrossRef] [PubMed]

2. Barr, S.; Gilg, A.W. Conceptualizing and analyzing household attitudes and actions to a growing environmental problem. Development and application of a framework to guide local waste policy. Appl. Geogr. 2005, 25, 226-247. [CrossRef]

3. Troschinetz, A.M.; Mihelcic, J.R. Sustainable recycling of municipal solid waste in developing countries. Waste Manag. 2009, 29, 915-923. [CrossRef] [PubMed]

4. Tadesse, T. Environmental concern and its implication to household waste separation and disposal: Evidence from Mekelle, Ethiopia. Resour. Conserv. Recy. 2009, 53, 183-191. [CrossRef]

5. Kurisu, K.H.; Bortoleto, A.P. Comparison of waste prevention behaviors among three Japanese megacity regions in the context of local measures and socio-demographics. Waste Manag. 2011, 3, 1441-1449. [CrossRef] [PubMed]

6. Purcell, M.; Magette, W.L. Attitudes and behavior towards waste management in the Dublin, Ireland. Waste Manag. 2010, 30, 1997-2006. [CrossRef] [PubMed]

7. Coelho, T.; Castro, R.; Gobbo, J.A. PET containers in Brazil: Opportunities and challenges of a logistics model for post-consumer waste recycling. Resour. Conserv. Recy. 2011, 55, 291-299. [CrossRef]

8. Karani, P.; Jewasikiewitz, S.M. Waste Management and Sustainable Development in South Africa. Environ. Dev. Sustain. 2006, 9, 163-185. [CrossRef]

9. Mohan, N.; Selladurai, V.; Santhi, P. Unsustainable development to sustainable development: A conceptual model. Manag. Environ. Qual. Int. J. 2006, 17, 654-672. [CrossRef]

10. Yau, Y. Domestic waste recycling, collective action and economic incentive: The case in Hong Kong. Waste Manag. 2010, 30, 2440-2447. [CrossRef] [PubMed]

11. Tonglet, M.; Phillips, P.; Bates, M. Determining the drivers for householder pro-environmental behavior: Waste minimization compared to recycling. Resour. Conserv. Recy. 2004, 42, 27-48. [CrossRef]

12. Salhofer, S.; Obersteiner, G.; Schneider, F.; Lebersorger, S. Potentials for the prevention of municipal solid waste. Waste Manag. 2008, 28, 245-259. [CrossRef] [PubMed]

13. Wang, J.; Han, L.; Li, S. The collection system for residential recyclables in communities in Haidian District, Beijing: A possible approach for China recycling. Waste Manag. 2008, 28, 1672-1680. [CrossRef] [PubMed]

14. Prestin, A.; Pearce, K.E. We care a lot: Formative research for a social marketing campaign to promote school-based recycling. Resour. Conserv. Recy. 2010, 54, 1017-1026. [CrossRef]

15. Schoot, B.J.; Azadi, H.; Ho, P. Sustainable recycling model: A comparative analysis between India and Tanzania. Resour. Conserv. Recy. 2011, 55, 344-355. [CrossRef]

16. Lee, S.; Paik, H.S. Korean household waste management and recycling behavior. Build. Environ. 2011, 46, 1159-1166. [CrossRef]

17. Cândido, L.; Kindlein, W.; Demori, R.; Carli, L.; Mauler, R.; Oliveira, R. The recycling cycle of materials as a design project tool. J. Clean Prod. 2011, 19, 1438-1445. [CrossRef]

18. Ekere, W.; Mugisha, J.; Drake, L. Factors influencing waste separation and utilization among households in the Lake Victoria crescent, Uganda. Waste Manag. 2009, 29, 3047-3051. [CrossRef] [PubMed]

19. Muñoz-Cadena, C.E.; Arenas-Huertero, F.J.; Ramón-Gallegos, E. Comparative analysis of the street generation of inorganic urban solid waste (IUSW) in two neighborhoods of Mexico City. Waste Manag. 2009, 29, 1167-1175. [CrossRef] [PubMed] 
20. Kaseva, M.E.; Mbuligwe, S.E. Appraisal of solid waste collection following private sector involvement in Dar es Salaam city, Tanzania. Habitat Int. 2005, 29, 353-366. [CrossRef]

21. Suttibak, S.; Nitivattananon, V. Assessment of factors influencing the performance of solid waste recycling programs. Resour. Conserv. Recy. 2008, 53, 45-56. [CrossRef]

22. Bolaane, B. Instruments for sustainable solid waste management in Botswana. Waste Manag. Res. 2004, 22, 342-353.

23. Karagiannidis, A.; Xirogiannopoulou, A.; Moussiopoulos, N. On the effect of demographic characteristics on the formulation of solid waste charging policy. Waste Manag. 2006, 26, 110-122. [CrossRef] [PubMed]

24. Vincente, P.; Reis, E. Segmenting households according to recycling attitudes in a Portuguese urban area. Resour. Conserv. Recy. 2007, 52, 1-12. [CrossRef]

25. The National Institute of Statistics and Geography (INEGI). Population and Housing Count 2010. Available online: http://www3.inegi.org.mx/sistemas/iter/entidad_indicador.aspx?ev=5 (accessed on 19 September 2016).

26. Sugeno, M.; Kang, G.T. Structure identification of fuzzy model. Fuzzy Sets Syst. 1988, 28, 15-33. [CrossRef]

27. Lazarevic, D.; Aoustin, E.; Buclet, N.; Brandt, N. Plastic waste management in the context of a European recycling society: Comparing results and uncertainties in a life cycle perspective. Resour. Conserv. Recy. 2010, 55, 246-259. [CrossRef]

28. Barr, S.; Gilg, A.W.; Ford, N. Defining the multi-dimensional aspects of household waste management: A study of reported behavior in Devon. Resour. Conserv. Recy. 2005, 45, 172-192. [CrossRef]

29. Zhuang, Y.; Wu, S.W.; Wang, Y.L.; Wu, W.X.; Chen, Y.X. Source separation of household waste: A case study in China. Waste Manag. 2008, 28, 2022-2030. [CrossRef] [PubMed]

30. Martin, M.; Williams, I.D.; Clark, M. Social, cultural and structural influences on household waste recycling: A case study. Resour. Conserv. Recy. 2006, 48, 357-395. [CrossRef]

31. Wilson, E.J. Life cycle inventory for municipal solid waste management. Waste Manag. Res. 2002, 20, 16-22. [CrossRef]

32. Kelly, T.C.; Mason, I.G.; Leiss, M.W.; Ganesh, S. University community responses to on-campus resource recycling. Resour. Conserv. Recy. 2006, 47, 42-55. [CrossRef]

33. Hansmann, R.; Bernasconi, P.; Smieszek, T.; Loukopoulos, P.; Scholz, R.W. Justifications and self-organization as determinants of recycling behavior: The case of used batteries. Resour. Conserv. Recy. 2006, 47, 133-159. [CrossRef]

34. Shen, J.; Saijo, T. Reexamining the relations between socio-demographic characteristics and individual environmental concern: Evidence from Shanghai data. J. Environ. Psychol. 2008, 28, 42-50. [CrossRef]

35. Babaei, A.A.; Alavi, N.; Goudarzi, G.; Teymouri, P.; Ahmadi, K.; Rafiee, M. Household recycling knowledge, attitudes and practices towards solid waste management. Resour. Conserv. Recy. 2015, 102, 94-100. [CrossRef]

36. Zen, I.S.; Noor, Z.Z.; Yusuf, R.O. The profiles of household solid waste recyclers and non-recyclers in Kuala Lumpur, Malaysia. Habitat Int. 2014, 42, 83-89. [CrossRef]

37. Acar, M.; Avci, D. An Adaptive Network-Based Fuzzy Inference System (ANFIS) for the prediction of stock market return: The case of the Istanbul Stock Exchange. Expert Syst. Appl. 2010, 37, 7908-7912.

38. Rahmanian, B.; Pakizeh, M.; Ali, S.; Mansoori, A.; Esfandyari, M.; Jafari, D.; Maddah, H.; Maskooki, A. Prediction of MEUF process performance using artificial neural networks and ANFIS approaches. J. Taiwan Inst. Chem. Eng. 2012, 43, 558-565. [CrossRef]

39. Signh, R.; Kainthola, A.; Singh, T.N. Estimation of elastic constant of rocks using an ANFIS approach. Appl. Soft Comput. J. 2012, 12, 40-45.

40. Sadiq, R.; Husain, T. A fuzzy-based methodology for an aggregative environmental risk assessment: A case study of drilling waste. Environ. Model. Softw. 2005, 20, 33-46. [CrossRef]

41. Vesely, S.; Klöckner, C.A.; Dohnal, M. Predicting recycling behaviour: Comparison of a linear regression model and a fuzzy logic model. Waste Manag. 2016, 49, 530-536. [CrossRef] [PubMed]

42. Caniani, D.; Lioi, D.S.; Mancini, I.M.; Masi, S. Application of fuzzy logic and sensitivity analysis for soil contamination hazard classification. Waste Manag. 2011, 31, 583-594. [CrossRef] [PubMed]

(C) 2017 by the authors; licensee MDPI, Basel, Switzerland. This article is an open access article distributed under the terms and conditions of the Creative Commons Attribution (CC BY) license (http:/ / creativecommons.org/licenses/by/4.0/). 